\title{
The Cambridge Mindreading Face-Voice Battery for Children (CAM-C): complex emotion recognition in children with and without autism spectrum conditions
}

\author{
Ofer Golan ${ }^{1 *}$, Yana Sinai-Gavrilov ${ }^{1}$ and Simon Baron-Cohen ${ }^{2,3}$
}

\begin{abstract}
Background: Difficulties in recognizing emotions and mental states are central characteristics of autism spectrum conditions (ASC). However, emotion recognition (ER) studies have focused mostly on recognition of the six 'basic' emotions, usually using still pictures of faces.

Methods: This study describes a new battery of tasks for testing recognition of nine complex emotions and mental states from video clips of faces and from voice recordings taken from the Mindreading DVD. This battery (the Cambridge Mindreading Face-Voice Battery for Children or (AM-C) was given to 30 high-functioning children with ASC, aged 8 to 11 , and to 25 matched controls.

Results: The ASC group scored significantly lower than controls on complex ER from faces and voices. In particular, participants with ASC had difficulty with six out of nine complex emotions. Age was positively correlated with all task scores, and verbal IQ was correlated with scores in the voice task. CAM-C scores were negatively correlated with parent-reported level of autism spectrum symptoms.

Conclusions: Children with ASC show deficits in recognition of complex emotions and mental states from both facial and vocal expressions. The CAM-C may be a useful test for endophenotypic studies of ASC and is one of the first to use dynamic stimuli as an assay to reveal the ER profile in ASC. It complements the adult version of the CAM Face-Voice Battery, thus providing opportunities for developmental assessment of social cognition in autism.
\end{abstract}

Keywords: Emotion recognition, Complex emotions, Facial expressions, Prosody, Theory of mind, Empathy, Autism spectrum conditions

\section{Background}

The ability to understand other people's emotional and other mental states underlies social skills and is a key process in the development of empathy [1]. The ability to discriminate emotions starts during the first year of life. Infants as young as 10 weeks of age respond differentially to their carer's emotional states, expressed in both the face and voice [2]. By 7 months, infants detect incongruence between facial and vocal expressions of emotions [3]. During their second and third years of life, children start using mental state words in their speech [4]. Throughout

\footnotetext{
* Correspondence: ofer.golan@biu.ac.il

'Department of Psychology, Bar-llan University, Ramat-Gan 5290002, Israel Full list of author information is available at the end of the article
}

childhood, the accuracy and speed of emotion recognition (ER) improve [5], children's emotional vocabulary expands, and they are able to recognize more subtle mental states [6]. Emotion and mental state recognition skills continue to develop into adolescence and adulthood.

Emotion and mental state recognition are core difficulties in autism spectrum conditions (ASC) [7-9]. Most ER studies carried out with individuals with ASC have focused on the recognition of six emotions (happiness, sadness, fear, anger, surprise and disgust). These so-called 'basic' emotions are expressed and recognized crossculturally [10] and are to some extent neurologically distinct [11], though it should be noted that the number of emotions that are recognized cross-culturally may exceed 
six [12]. In ASC, some studies report difficulties in recognition of basic emotions [13-16]. Other studies, however, have found no difficulties in recognition of the basic emotions in children with ASC [17-20]. In contrast, studies investigating recognition of complex emotions and other mental states by children with ASC have shown more conclusive results. Generally, complex emotions involve attributing a cognitive state as well as an emotion and are more context and culture dependent [11]. They may be belief- rather than situation-based emotions [21], for example, disappointed. They may also be self-conscious emotions, for example, proud or embarrassed [22]. Typically developing children start recognizing and verbally labelling complex emotions like embarrassment, pride and jealousy by the age of 7 $[21,23]$. Studies report deficits in complex ER in individuals with ASC on various tasks, including ER from pictures of the eyes [24], from facial expressions [25], from linguistic contextual cues [26,27] and from holistic, multimodal scenes $[28,29]$. These studies suggest that children with ASC, although initially delayed in the development of basic ER skills, may achieve this developmental milestone during their school years or successfully compensate for their basic ER difficulties through explicit cognitive, language-based or perceptual mechanisms [30]. An assessment of ER difficulties in children with ASC therefore needs to address more complex mental states. The current study focuses on recognition of complex emotions to fill a gap in the existing literature and to provide a new test of complex ER using dynamic stimuli.

Among adults with ASC, there is growing evidence for difficulties in the recognition of complex emotions or subtle versions of basic emotions [31-34]. However, as mentioned above, there are not many complex ER tasks available for children. Existing tasks have mostly used still pictures [24]. Those that included faces in motion [28] have tended to include only a narrow range of complex emotions. As far as we are aware, there has not yet been any study of children testing complex ER in voices alone. Therefore, there is a need for a test that assesses ER in a variety of complex emotions, in both visual and auditory channels, using motion in the visual task, to get closer to the demands of the real world, while using validated stimuli that are standardized and therefore useful for research and clinical purposes.

In this study, we present such a battery: 'The Cambridge Mindreading Face-Voice Battery for Children' (or the CAM-C). This is an adaptation of a complex ER battery for adults [34]. The CAM-C includes nine different complex emotions. The battery provides ER scores for faces and for voices, as well as for the number of emotions correctly recognized. The objectives of the current study were twofold: (a) to compare ER abilities of children with ASC and typically developing controls and (b) to examine the psychometric properties of the CAM-C battery, in terms of reliability, concurrent validity and ability to differentiate between children with ASC and typically developing children in ER skills.

Using this battery, we assessed differences between 8- and 11-year-old children with high-functioning ASC and a typically developing matched control group. We predicted that the ASC group would have lower scores on the battery tasks compared to controls. In addition, we predicted that CAM-C scores would correlate negatively with the level of autistic symptoms [24,29,35] and positively with age [36] and with IQ [37,38]. Correlations with the child version of the 'Reading the Mind in the Eyes' (RME) [39], an existing complex ER task, were also calculated to examine the CAM-C battery's concurrent validity.

\section{Methods \\ Participants}

The research was approved by the Cambridge University Psychology Research Ethics Committee. Participation required informed consent from parents and verbal assent from children. The ASC group comprised 30 children (29 boys and 1 girl), aged 8.2 to $11.8(M=9.7, \mathrm{SD}=1.2)$. Participants had all been diagnosed with ASC by a psychiatrist or clinical psychologist in specialist centres using established criteria $[40,41]$. They were recruited from a volunteer database (at www.autismresearchcentre.com) and a local clinic for children with ASC. A control group from the general population was matched to the clinical group. This comprised 25 children (24 boys and 1 girl), aged 8.2 to $12.1(M=10.0, \mathrm{SD}=1.1)$. They were recruited from a local primary school. Parents reported their children had no psychiatric diagnoses and special educational needs, and none had a family member diagnosed with ASC. All participants were given the Wechsler Abbreviated Scale of Intelligence (WASI) and scored above 80 on both verbal and performance scales. To exclude ASC, participants' parents filled in the Childhood Autism Spectrum Test (CAST) [42]. None of the control participants scored above the cutoff point of 15. All but two participants in the ASC group scored above the cut-off. These two participants scored below the cut-off due to several unanswered items. However, since the CAST is a parental report screening questionnaire, the clinical diagnosis received earlier was deemed more valid and these participants were not excluded from the sample. The two groups were matched on sex, age, verbal IQ and 
performance IQ. The groups' background data appears in Table 1.

\section{Instruments}

\section{The CAM-C: test development}

Nine emotional concepts were selected from a developmentally tested emotional taxonomy [23,43]: amused, bothered, disappointed, embarrassed, jealous, loving, nervous, undecided, and unfriendly. The selected concepts included emotions that are developmentally significant, subtle variations of basic emotions that have a mental component and emotions and mental states that are important for everyday social functioning.

For each emotional concept, three face items and three voice items were created using silent video clips of facial expressions and audio clips of short verbalizations spoken in emotional intonation (all 3 to $5 \mathrm{~s}$ long). The face and voice clips were taken from an interactive guide to emotions (www.jkp.com/mindreading) [43]. Faces and voices were portrayed by professional actors, both male and female, of different age groups and ethnicities. Three foils were set for each item, using the emotion taxonomy. Selected foils were either the same developmental level or easier levels than the target emotion. Foils for vocal items were selected so they could match the verbal content of the scene but not the intonation (for example, 'You've done it again', spoken in amused intonation, had interested, unsure and thinking as foils). All foils were then reviewed by two independent judges (doctoral students, who specialize in emotion research), who had to agree no foil was too similar to its target emotion. Agreement was initially reached for $91 \%$ of the items. Items on which consensus was not reached were altered until full agreement was achieved for all items.

Two tasks, one for face recognition and one for voice recognition, were created using DMDX experimental software [44]. Each task started with an instruction slide, asking participants to choose the answer that best describes how the person in each clip is feeling. The instructions were followed by two practice items. In the face task, four emotion labels, numbered from 1 to 4 ,

Table 1 Means, SDs and ranges of chronological age, CAST and WASI scores for ASC and control groups

\begin{tabular}{llllllll}
\hline & \multicolumn{2}{l}{ ASC group $(\boldsymbol{n}=\mathbf{3 0})$} & & \multicolumn{2}{l}{ Control group $(\boldsymbol{n}=\mathbf{2 5})$} & \multirow{2}{*}{$\boldsymbol{t}(\mathbf{5 3})$} \\
\cline { 2 - 3 } & Mean (SD) & Range & & Mean (SD) & Range & \\
\hline CAST & $19.7(4.3)$ & $11-28$ & & $3.4(1.7)$ & $0-6$ & $18.33^{* *}$ \\
Age & $9.7(1.2)$ & $8.2-11.8$ & & $10.0(1.1)$ & $8.2-12.1$ & .95 \\
WASI VIQ & $112.9(12.9)$ & $88-143$ & & $114.0(12.3)$ & $88-138$ & .32 \\
WASI PIQ & $111.0(15.3)$ & $84-141$ & & $112.0(13.3)$ & $91-134$ & .27 \\
WASI FIQ & $113.5(11.8)$ & $96-138$ & & $114.8(11.9)$ & $95-140$ & .39 \\
\hline
\end{tabular}

CAST, Childhood Autism Spectrum Test; WASI, Wechsler Abbreviated Scales of Intelligence. ${ }^{* *} P<.001$. For all the other measures, $P>.1$. were presented after playing each clip. Items were played in a random order. An example question showing one frame from one of the clips is shown in Figure 1. In the voice task, the four numbered answers were presented before and while each item was played, to prevent working memory overload. This prevented randomizing item order in the voice task. Instead, two versions of the task were created, with reversed order, to avoid an order effect. A handout with definitions for all the emotion words used in the tasks was prepared.

The tasks were then piloted with 16 children - 2 girls and 2 boys from 4 age groups - 8, 9, 10 and 11 years of age. Informed consent was obtained from parents, and verbal assent was given by children prior to participation in the pilot. Children were randomly selected from a local mainstream school and tested there individually. The tasks were played to them on two laptop computers, using headphones for the voice task. To avoid confounding effects due to reading difficulties, the experimenter read the instructions and possible answers to the children and made sure they were familiar with all the words, using the definition handout, where necessary. Participants were then asked to press a number from 1 to 4 to choose their answer. After choosing an answer, the next item was presented. No feedback was given during the task.

Next, item analysis was carried out. Items were included if the target answer was picked by at least half of the participants and if no foil was selected by more than a third of the participants $(P<.05$, binomial test). Items which failed to meet these criteria were matched with new foils and played to a different group of 16 children,

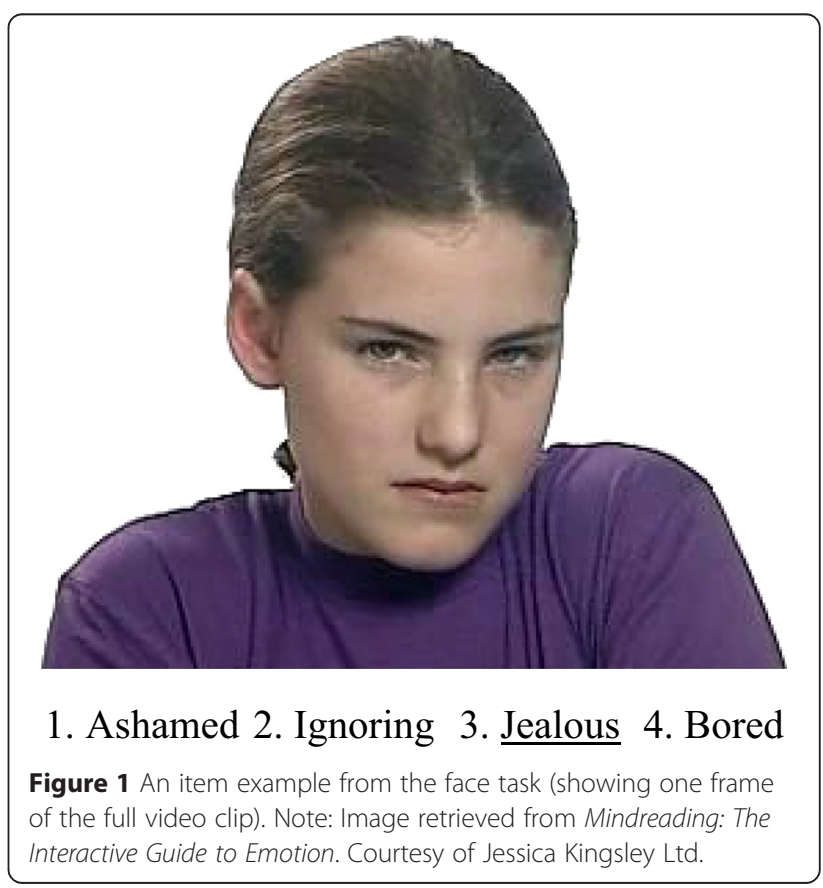


until they all met criteria. The final task included 27 items in the face task and 27 in the voice task, representing the nine emotional concepts. In addition, the following measures were used:

\section{Childhood Autism Spectrum Test (CAST) [42]}

The CAST is a parental questionnaire designed specifically to screen school-age populations for ASC. Scores range from 0 to 31, and the higher the score, the more autism spectrum features the child possesses. In a community sample study [45], the CAST was validated against existing validated diagnostic protocols. With a cut-off score of 15, it discriminated well between children with ASC and typically developing children, with a sensitivity of $100 \%$ and specificity of $97 \%$. Its test-retest reliability in a community sample was 0.83 [46].

\section{Reading the Mind in the Eyes (RME) - child version [39]}

This test of complex mental state recognition consists of 28 photographs of the eye region of the human face, each surrounded by four words. Participants are asked to pick which of the four words best describes what the person in the photo is thinking or feeling. The task is a verbally simplified version of the RME test for adults [24,47]. Children with ASC score significantly lower on this task, compared to matched controls from the general population. Testretest reliability of the RME, calculated for a subsample of 21 children from the ASC group who took the task twice with a 10 - to 15 -week time difference, was $r=.64(P<.01)$.

\section{Wechsler's Abbreviated Scales of Intelligence (WASI) [48]}

This brief measure of intelligence consists of four subtests which provide verbal, performance and full-scale IQ scores. The verbal IQ (VIQ) is comprised of the Vocabulary and Similarities subtests, and the performance IQ (PIQ) includes the Block Design and Matrix Reasoning subtests. These four comprise the Full-Scale IQ (FIQ) and take approximately $30 \mathrm{~min}$ to administer. The WASI has been shown to have an internal consistency reliability of .96 and was originally validated against full measures of intelligence for children [48].

\section{Procedure}

Participants with ASC were tested at the Autism Research Centre in Cambridge. Controls were tested at a local school. All participants were tested individually. Prior to undertaking the ER tasks, children completed the WASI, in order to confirm that none had an IQ below 70. The final version of the tasks was presented to the participants on a laptop computer with a 15-in. screen. Headphones were provided for the voice task. The experimenter read the instructions and the questions and answers for all items with the participants, and asked if they were familiar with all the possible answers. If the child was not familiar with a word, it was defined using the definition handout. There was no time limit to answer each item. Completion of the whole battery took about $45 \mathrm{~min}$, including breaks. The RME task was completed during the same session and took about $15 \mathrm{~min}$. Administration order of the three ER tasks (CAM-C face, CAM-C voice and RME) was randomized. Participants' parents filled in the CAST in advance.

\section{Results}

Facial and vocal scores were calculated as the number of correct answers in each of the tasks. Emotional concepts were counted as correctly recognized if at least four out of the concept's six items were answered correctly $(P<.05$, binomial test). All participants scored above chance on the face task, and all but one participant from the ASC group scored above chance on the voice task. There were no ceiling effects.

\section{Between-group findings}

In order to check for group and modality differences on complex ER, a multivariate analysis of variance (MANOVA) with repeated measures was conducted, with modality (face, voice) as the within-subject factor and group (ASC, controls) as the between-group factor. The analysis yielded a significant main effect for group $(F[1,53]=21.62$, $\left.P<.001, \eta^{2}=.29\right)$, with the control group scoring higher than the ASC group. Modality had a significant main effect $\left(F[1,53]=5.17, P<.05, \eta^{2}=.09\right)$, with participants scoring higher on the voice task. No significant interactions of group and modality were found $(F[1,53]=.22$, n.s.). Univariate analyses of variance for the face and voice tasks showed a lesser performance in the ASC group, compared to the control group, on both tasks. A separate univariate analysis of variance for the number of emotional concepts correctly recognized by participants yielded a significant group effect, with the control group recognizing significantly more emotional concepts than the ASC group. The task scores and the number of emotional concepts correctly recognized by participants in the two groups are presented in Table 2.

In order to compare the recognition of individual emotional concepts between the two groups, goodness-of-fit tests were performed for the proportions of participants who correctly recognized each concept in the two groups. Table 3 shows proportions of participants of the two

Table 2 Group means and standard deviations, $\boldsymbol{F}$ scores, and effect sizes for CAM-C battery

\begin{tabular}{lllll}
\hline & ASC & Control & $\boldsymbol{F}(\mathbf{1}, \mathbf{5 3})$ & $\boldsymbol{\eta \mathbf { 2 }}$ \\
\hline Face task $(\max =27)$ & $15.0(3.9)$ & $19.2(3.7)$ & $17.1^{* *}$ & .25 \\
Voice task $(\max =27)$ & $16.4(3.6)$ & $20.1(3.5)$ & $17.6^{* *}$ & .26 \\
Concepts recognized $(\max =9)$ & $4.6(1.7)$ & $6.6(1.9)$ & $20.22^{* *}$ & .28 \\
\hline
\end{tabular}

**P< $<.001$ 


\begin{tabular}{|c|c|c|c|}
\hline $\begin{array}{l}\text { Emotional } \\
\text { concept }\end{array}$ & $\begin{array}{l}\text { ASC } \\
(n=30)\end{array}$ & $\begin{array}{l}\text { Controls } \\
(n=25)\end{array}$ & $x^{2}(1)$ \\
\hline Unfriendly & $30 \%$ & $60 \%$ & $4.99^{*}$ \\
\hline Disappointed & $53 \%$ & $84 \%$ & $5.83^{*}$ \\
\hline Embarrassed & $33 \%$ & $44 \%$ & 0.66 \\
\hline Jealous & $60 \%$ & $88 \%$ & $5.39^{*}$ \\
\hline Loving & $73 \%$ & $72 \%$ & 0.01 \\
\hline Nervous & $40 \%$ & $72 \%$ & $5.63^{*}$ \\
\hline Bothered & $53 \%$ & $84 \%$ & $5.83^{*}$ \\
\hline Amused & $40 \%$ & $72 \%$ & $5.63^{*}$ \\
\hline Undecided & $73 \%$ & $84 \%$ & 0.91 \\
\hline
\end{tabular}

groups who recognized each of the nine concepts. As shown in Table 3, compared to the control group, a significantly smaller proportion of individuals in the ASC group correctly recognized unfriendly, disappointed, jealous, nervous, bothered and amused.

\section{Psychometric properties of the CAM-C}

Over and above group, participants scored an average of $16.89(\mathrm{SD}=4.36)$ on the face task and $18.07(\mathrm{SD}=3.97)$ on the voice task and correctly recognized on average 5.49 ( $\mathrm{SD}=2.08)$ emotional concepts. As reported above, a significant difference between face and voice task scores was found. However, when participants' WASI verbal IQ scores were statistically controlled for, this difference became non-significant.

In order to investigate the relation between CAM-C scores and other study measures, correlation analysis was conducted. Due to the relatively small group size, and since there were no differences between correlations in the ASC group and the control group, correlations were only calculated for the two groups combined. The analysis, presented in Table 4, shows the hypothesized negative correlations between CAST scores and CAM-C scores were indeed significant. Age was also positively correlated with CAM-C scores. WASI verbal IQ was positively correlated only with vocal task scores and with the number of emotional concepts correctly recognized.

Table 4 Correlations of CAM-C scores with background measures and with an external criterion

\begin{tabular}{llllll}
\hline & CAST & Age & WASI VIQ & WASI PIQ & RME \\
\hline Face task & $-.54^{* *}$ & $.53^{* *}$ & .21 & .04 & $.35^{* *}$ \\
Voice task & $-.48^{* *}$ & $46^{* *}$ & $.42^{* *}$ & .00 & $.40^{* *}$ \\
Concepts recognized & $-.53^{* *}$ & $.57^{* *}$ & $.35^{* *}$ & .08 & $.36^{* *}$ \\
\hline
\end{tabular}

CAST, Childhood Autism Spectrum Test; RME, Reading the Mind in the Eyes - children version; WASI, Wechsler Abbreviated Scale of Intelligence. ${ }^{* *} P<.01$.
WASI performance IQ was unrelated to any of the tasks. In addition, CAM-C face and voice task scores were positively correlated with each other $(r=.60, P<.001)$.

Power calculations for the tasks (with $\alpha=0.01$ ) show they distinguish well between the ASC and control groups: $1-\beta=0.951$ for the face task, 0.923 for the voice task and 0.949 for the number of emotional concepts recognized. In order to examine test-retest reliability, 21 children from the ASC group took the CAM-C twice, with 10 to 15 weeks between the two assessments. This was part of an intervention study in which these children served as no-intervention controls. Test-retest correlations were $r=.74$ for the face task and $r=.76$ for the voice task $(P<.001$ for both). Finally, the child version of the RME correlated positively with all CAM-C scores (with the face task: $r=.35$, with the voice task: $r=.40$, with the number of emotional concepts correctly recognized: $r=.36, P<.01$ for all). This served as an external criterion and provided support for concurrent validity.

\section{Discussion}

The current study tested if there are differences in complex ER between children with ASC and typically developing children. This was examined using the CAM-C, a new battery, testing complex ER in both facial and vocal expressions. As predicted, the ASC group had more difficulties recognizing complex emotions from faces and voices and recognized fewer emotional concepts, compared to the control group, even when controlling for age and verbal IQ. These results support previous findings of difficulties in complex emotion recognition in children with ASC [25,27-29,49]. The CAM-C battery demonstrated good test-retest reliability and concurrent validity. Scores were positively associated with participants' age and negatively associated with the level of autistic symptomatology.

Children with ASC showed specific difficulties in the recognition of six out of the nine complex emotions and mental states tested: disappointed, jealous, nervous, unfriendly, bothered and amused. The grounds for these difficulties are discussed in reference to two main factors characterizing complex emotions [4,11]: complexity (that is, combining several basic emotions and mental states) and subtlety (that is, toning down an emotional expression or attempting to conceal it).

Typically developing children have been found to understand and recognize complex emotions such as jealous, disappointed and embarrassed between the ages of 7 and 10 [36,50]. Indeed, our findings show that more than $80 \%$ of the control group recognized jealousy and disappointment successfully. However, only $60 \%$ of the participants in the ASC group recognized the concept jealous, which includes restrained hostility towards someone as a result of social comparison [51]. Common 
errors included mislabelling facial expressions of jealous as disappointed, possibly because of focusing on the mouth region of the face, which resembles being unhappy. Relying on the mouth area for ER while disregarding the eyes is characteristic of people with ASC [47,52], particularly in complex emotions [31]. Whereas this may sometimes suffice when interpreting basic emotions (for example, happy or sad), configural cues, as well as theory of mind, are required for recognition of complex emotions like jealous. Voice items for the concept of jealous were mislabelled as teasing ('I can do better than you') or bossy ('I deserve that car more than him'), failing to combine linguistic and paralinguistic components of the verbalizations.

Children with ASC also showed difficulties in the recognition of disappointment, which involves sadness due to a failed expectation [53]. Only 53\% of the participants in the ASC group correctly recognized this emotion, compared to $84 \%$ of the controls. Common errors included mislabelling it as thinking and unsure for faces, possibly due to the gaze being directed downwards, away from the camera. Participants may have failed to integrate this cue with the unhappy mouth cue. Disappointed voice items were commonly mislabelled as ashamed ('I should have won') and hurt ('I tried so hard'). Whereas these labels capture the emotion's negative valence, they do not elicit the failed expectation from the verbalizations.

Interestingly, no group difference was found for the recognition of embarrassed. Though a larger proportion of controls (44\%) recognized this emotion, compared to the ASC group (33\%), this difference was not significant. Common errors for face items in both groups included sad and jealous. Voice items were mislabelled as afraid ('Do you think anyone saw me?') and wishful ('Oh, I wish it hadn't happened'). Since embarrassment is a complex emotion, dependent on the real (or imagined) presence of others [54], the correct perception of this emotion would be expected to be facilitated by contextual cues, which were not available in the CAM-C. A task employing holistic situations in context [29] may be useful to examine the ER of embarrassment.

As noted, participants in the ASC group had significant difficulties with emotional concepts that form more subtle representations of basic emotions. For example, only 53\% of children with ASC (compared to 84\% of controls) correctly recognized bothered, a form of mild anger. Common mistakes included disbelieving and bored on the face task, and unsure ('What are you doing here?') and disbelieving ('I wish I didn't have to do it') on the voice task. These demonstrate how, when emotional cues are more subtle, children with ASC may miss their presence and interpret them as mental states. Another example for difficulties recognizing subtle expressions can be seen in the example of nervous, a mild expression of fear, recognized by only $40 \%$ of the ASC group. Common errors were mislabelling a face item as annoyed and voice items as disgusted ('Don't put that near me'), or an emotionally neutral option, such as asking ('How many people are out there?'). These examples show again how in ASC intonation may be disregarded and verbal content may be used to recognize the speaker's emotion/mental state. An fMRI study of adults with ASC found that the amygdala, a key brain area underlying the detection of fear in others, does not respond differentially to expressions of subtle fear [55].

Interestingly, there was no group difference in the recognition of the positive emotion loving. This is consistent with past research showing specific difficulties to others' negative emotions in children with ASC $[56,57]$. Nevertheless, the ASC group had difficulties in the recognition of the positive emotion amused, a form of reflective joy [58]. Participants with ASC mislabelled it as interested or curious on the face task, and as interested ('You've done it again') or excited ('Imagine that') on the voice task, relying on the linguistic cues while missing the paralinguistic cues of the speaker's smile [59]. These demonstrate that even in the positive emotion domain, as complexity increases, it is harder for children with ASC to integrate the relevant cues, resulting in a misattribution of emotion.

Only $30 \%$ of the participants with ASC correctly recognized the concept unfriendly. The ASC group mislabelled unfriendly faces as afraid, disgusted and shy. These errors were probably related to the actors moving their faces away from the camera and looking sideways. Failing to recognize a protagonist as unfriendly, as well as mistaking others' amusement for interest, may be related to the increased risk of teasing and bullying that children with ASC experience $[60,61]$.

Two patterns emerge from the results, which may account for the errors made by participants in the ASC group in complex ER. First, the relative difficulty in interpreting gaze, characteristic of individuals with ASC, may underlie the pattern of results found in the unfriendly, disappointed and jealous face task items. Previous studies have shown that individuals with ASC show diminished performance compared to typically developing controls in inferring mental states from the eyes $[24,62]$ and atypical eye-gaze processing patterns $[63,64]$.

Second, processing of emotion in prosody should be considered in relation to lowered performance of participants with ASC in the voice items. The processing of affective prosody has been found to be impaired among individuals with ASC $[65,66]$, who may show overreliance on verbal information on the account of change patterns in prosodic cues such as pitch and volume that may be more relevant for the recognition of emotion.

The positive correlations of all task scores with age, independent of diagnosis, suggest that ER skills continue 
to develop in both typically developing children and children with ASC. In addition, as predicted, CAM-C scores were negatively correlated with the participants' level of autism spectrum symptoms. This finding highlights the ER profile as a potential marker of ASC. Furthermore, since the range of CAST scores was quite narrow in both groups, correlations with the level of autistic traits were potentially lower than they could be if the autism spectrum was more fully represented, for example, by including undiagnosed siblings of children with ASC $[67,68]$.

As predicted, complex emotion voice task scores were positively correlated with verbal ability. This may be related to the need for integration of the stimuli's verbal content and intonation, which may depend on verbal ability. It may also demonstrate the compensatory reliance on verbal content, employed by individuals with ASC on emotion recognition tasks $[30,65]$, which may be compromised in individuals with poorer verbal abilities. The correlation of verbal ability with the voice task scores may also explain the significant difference between face and voice task scores, over and above group. Indeed, when verbal ability was entered into a MANCOVA as a covariate, the difference between face and voice tasks became non-significant, while the group difference on both tasks remained significant.

Several issues are noteworthy when examining the psychometric properties of the CAM-C. Power calculations for the CAM-C tasks indicated that the battery differentiates well between the two study groups. Test-retest correlations computed for the battery (.74 to .76) suggest that this measure of complex ER is consistent over time. Furthermore, the positive correlations of CAM-C scores with the RME task provide the battery with important measures of external validity. These correlations were significant but moderate (.35 to .40 ), suggesting they may test different aspects of a common skill. Power levels of the CAM-C show it is sensitive to group differences across all tasks and scores. These data provide support for the CAM-C as a valid and reliable measure of complex ER skills.

\section{Limitations and directions for future research}

Several limitations should be noted. In the current study, validation of participants' clinical diagnosis in the ASC group was based on the CAST, a screener for ASC that is based on parental report. Future studies should validate participants' diagnosis on the basis of independent standardized measures, such as the ADOS-2 [69], which could also contribute to the understanding of the association between ASC symptomatology and complex ER deficits. Additional research of the CAM-C is also needed to further investigate its psychometric properties, such as sensitivity and specificity, with a wider age range, a wider range of validation criteria and a larger sample.
Future research may address questions regarding the ability of the CAM-C to differentiate between ASC and other clinical groups, given that it is significantly correlated with the level of autism symptoms. Finally, some studies have examined the question of scan paths in ER using eye tracking [31]. The application of such a paradigm in the study of the CAM-C might further elucidate the mechanisms underlying the profile found among children with ASC in the recognition of complex emotions from dynamic facial stimuli.

\section{Conclusions}

This new battery for testing complex emotion recognition, in the face (using dynamic stimuli) and in the voice, reveals that 8- to 11-year-old children with ASC have difficulties in complex emotion and mental state recognition in both faces and voices. The CAM-C may be useful in intervention research to monitor improvements in this skill or to augment diagnostic assessments [70-72]. It also lends itself to neuroimaging and developmental research in being standardized and validated and may serve as an endophenotypic stimulus set [73]. It will be interesting to apply the CAM-C to other clinical groups in order to establish its sensitivity and specificity to detect strengths and difficulties in ER.

\section{Abbreviations}

ASC: autism spectrum conditions; CAM-C: Cambridge Mindreading Face-Voice Battery for Children; CAST: Childhood Autism Spectrum Test; ER: emotion recognition; RME: Reading the Mind in the Eyes; WASI: Wechsler Abbreviated Scale of Intelligence.

\section{Competing interests}

The authors declare that they have no competing interests. The CAM-C is derived from the Mindreading DVD that is published by Jessica Kingsley Ltd (www.jkp.com/mindreading), profits from which go to autism research. The CAM-C is available as free download for use in not-for-profit research from www.autismresearchcentre.com.

\section{Authors' contributions}

OG and SBC designed the study. Data were collected by OG, who undertook all statistical analyses and drafted the manuscript. OG, YSG and SBC contributed to subsequent drafts and the final submitted manuscript. All authors read and approved the final version of the manuscript.

\section{Acknowledgements}

OG was supported by the Wingate Foundation, the Corob Charitable Trust and B'nai B'rith Scholarships. SBC was supported by the Shirley Foundation, the Medical Research Council (MRC) UK, the Wellcome Trust and the Autism Research Trust. This study was conducted in association with the NIHR CLAHRC-EOE, EU ASC-Inclusion, and EU-AIMS. We would like to thank the Wirral Autistic Society, Umbrella Autism Cambridgeshire, the Hertfordshire Autistic Resource Centre, Brookside Family Consultation Clinic, Mayfield Primary School and Kings Hedges Primary School for their help with recruiting participants. We are grateful to Jacqueline Hill, Chris Ashwin, Sally Wheelwright, Yael Golan, Sarah Johnson and Emma Chapman for their help, and to Bhisma Chakrabarti for valuable discussions.

\section{Author details}

'Department of Psychology, Bar-llan University, Ramat-Gan 5290002, Israel. ${ }^{2}$ Autism Research Centre, Department of Psychiatry, Cambridge University, Douglas House, 18b Trumpington Road, Cambridge CB2 2AH, UK. 
${ }^{3}$ Cambridgeshire and Peterborough NHS Foundation Trust, CLASS Clinic, Fulbourn Hospital, Cambridge CB21 5EF, UK.

\section{Received: 6 October 2014 Accepted: 30 March 2015} Published online: 23 April 2015

\section{References}

1. Baron-Cohen S. The extreme male brain theory of autism. Trends Cogn Sci. 2002;6:248-54

2. Haviland JM, Lelwica M. The induced affect response: 10-week-old infants' responses to three emotion expressions. Dev Psychol. 1987;23:97-104.

3. Caron AJ, Caron RF, MacLean DJ. Infant discrimination of naturalistic emotional expressions: the role of face and voice. Child Dev. 1988:59:604-16.

4. Izard CE, Harris PL. Emotional development and developmental psychopathology. In: Cohen DJ, Cicchetti DV, editors. Theory and methods, vol. 1. Oxford, England: John Wiley \& Sons; 1995. p. 467-503.

5. De Sonneville LM, Verschoor CA, Njiokiktjien C, Op het Veld V, Toorenaar N, Vranken M. Facial identity and facial emotions: speed, accuracy, and processing strategies in children and adults. J Clin Exp Neuropsychol. 2002;24:200-13.

6. Vicari S, Reilly JS, Pasqualetti P, Vizzotto A, Caltagirone C. Recognition of facial expressions of emotions in school-age children: the intersection of perceptual and semantic categories. Acta Paediatr. 2000;89:836-45.

7. American Psychiatric Association. Diagnostic and statistical manual of mental disorders, 5th edition - DSM-5. Washington DC: American Psychiatric Association; 2013.

8. Baron-Cohen S. Mindblindness: an essay on autism and theory of mind. Boston: MIT Press/Bradford Books; 1995.

9. Hobson RP. Understanding persons: the role of affect. In: Baron-Cohen S, Tager-Flusberg H, Cohen DJ, editors. Understanding other minds. London: Oxford University Press; 1994. p. 204-27.

10. Ekman P. Facial expression and emotion. Am Psychol. 1993;48:384-92.

11. Griffiths P. What emotions really are: the problem of psychological categories. Chicago, London: University of Chicago Press; 1997.

12. Baron-Cohen S, Riviere A, Cross P, Fukushima M, Bryant C, Sotillo M, et al. Reading the mind in the face: a cross-cultural and developmental study. Vis Cogn. 1996:3:39-59.

13. Celani G, Battacchi MW, Arcidiacono L. The understanding of the emotional meaning of facial expressions in people with autism. J Autism Dev Disord. 1999:29:57-66

14. Deruelle C, Rondan C, Gepner B, Tardif C. Spatial frequency and face processing in children with autism and Asperger syndrome. J Autism Dev Disord. 2004;34:199-210.

15. Hobson RP. The autistic child's appraisal of expressions of emotion. J Child Psychol Psychiatry. 1986;27:321-42.

16. Loveland KA, Tunali Kotoski B, Chen R, Brelsford KA. Intermodal perception of affect in persons with autism or Down syndrome. Dev Psychopathol. 1995:7:409-18.

17. Boucher J, Lewis V, Collis GM. Voice processing abilities in children with autism, children with specific language impairments, and young typically developing children. J Child Psychol Psychiatry. 2000;41:847-57.

18. Grossman JB, Klin A, Carter AS, Volkmar FR. Verbal bias in recognition of facial emotions in children with Asperger syndrome. J Child Psychol Psychiatry. 2000;41:369-79.

19. Castelli F. Understanding emotions from standardized facial expressions in autism and normal development. Autism. 2005;9:428-49.

20. Tracy JL, Robins RW, Schriber RA, Solomon M. Is emotion recognition impaired in individuals with autism spectrum disorders? J Autism Dev Disord. 2011:41:102-9.

21. Harris PL. Children and emotion: the development of psychological understanding. Oxford: Blackwell; 1989.

22. Kasari C, Chamberlain B, Bauminger N. Social emotions and social relationships: can children with autism compensate? In: Burack JA, Charman T, Yirmiya N, Zelazo PR, editors. The development of autism: perspectives from theory and research. Mahwah, NJ, US: Lawrence Erlbaum; 2001 p. 309-23.

23. Baron-Cohen S, Golan O, Wheelwright S, Granader Y. Emotion word comprehension from 4-16 years old: a developmental survey. Front Evol Neurosci. 2010;2:12.

24. Baron-Cohen S, Wheelwright S, Hill J, Raste Y, Plumb I. The "Reading the Mind in the Eyes" Test revised version: a study with normal adults, and adults with Asperger syndrome or high-functioning autism. J Child Psychol Psychiatry. 2001;42:241-51.

25. Capps L, Yirmiya N, Sigman M. Understanding of simple and complex emotions in non-retarded children with autism. J Child Psychol Psychiatry. 1992;33:1169-82

26. Baron-Cohen S, O'Riordan M, Stone VE, Jones R, Plaisted K. Recognition of faux pas by normally developing children with Asperger syndrome or highfunctioning autism. J Autism Dev Disord. 1999:29:407-18.

27. Happe FG. An advanced test of theory of mind: understanding of story characters' thoughts and feelings by able autistic, mentally handicapped, and normal children and adults. J Autism Dev Disord. 1994;24:129-54.

28. Yirmiya N, Sigman MD, Kasari C, Mundy P. Empathy and cognition in highfunctioning children with autism. Child Dev. 1992;63:150-60.

29. Golan O, Baron-Cohen S, Golan Y. The 'Reading the Mind in Films' Task [child version]: complex emotion and mental state recognition in children with and without autism spectrum conditions. J Autism Dev Disord. 2008:38:1534-41.

30. Harms MB, Martin A, Wallace GL. Facial emotion recognition in autism spectrum disorders: a review of behavioral and neuroimaging studies. Neuropsychol Rev. 2010;20:290-322

31. Rutherford M, Towns AM. Scan path differences and similarities during emotion perception in those with and without autism spectrum disorders. J Autism Dev Disord. 2008:38:1371-81.

32. Sawyer AC, Williamson P, Young RL. Can gaze avoidance explain why individuals with Asperger's syndrome can't recognise emotions from facial expressions? J Autism Dev Disord. 2012;42:606-18.

33. Shamay-Tsoory SG. Recognition of 'fortune of others' emotions in Asperger syndrome and high functioning autism. J Autism Dev Disord. 2008:38:1451-61.

34. Golan O, Baron-Cohen S, Hill J. The Cambridge Mindreading (CAM) FaceVoice Battery: testing complex emotion recognition in adults with and without Asperger syndrome. J Autism Dev Disord. 2006;36:169-83.

35. Dennis M, Lockyer L, Lazenby AL. How high-functioning children with autism understand real and deceptive emotion. Autism. 2000:4:370-81.

36. Herba C, Phillips M. Annotation: Development of facial expression recognition from childhood to adolescence: behavioural and neurological perspectives. J Child Psychol Psychiatry. 2004;45:1185-98.

37. Dyck MJ, Ferguson K, Shochet IM. Do autism spectrum disorders differ from each other and from non-spectrum disorders on emotion recognition tests? Eur Child Adolesc Psychiatry. 2001;10:105-16.

38. Golan O, Baron-Cohen S, Hill JJ, Rutherford MD. The 'Reading the Mind in the Voice' test - Revised: a study of complex emotion recognition in adults with and without Autism Spectrum Conditions. Journal of Autism and Developmental Disorders. 2007;37:1096-106.

39. Baron-Cohen S, Wheelwright S, Spong A, Scahill VL, Lawson J. Are intuitive physics and intuitive psychology independent? A test with children with Asperger syndrome. Journal of Developmental and Learning Disorders. 2001:5:47-78.

40. American-Psychiatric-Association. DSM-IV-TR Diagnostic and statistical manual of mental disorders. 4th ed. Washington DC: American Psychiatric Association; 2000. Text Revision.

41. World-Health-Organization. ICD-10 - International classification of diseases. 10th ed. Geneva, Switzerland: World Health Organization; 1994.

42. Scott FJ, Baron-Cohen S, Bolton P, Brayne C. The CAST (Childhood Asperger Syndrome Test): preliminary development of a UK screen for mainstream primary-school-age children. Autism. 2002;6:9-31.

43. Baron-Cohen S, Golan O, Wheelwright S, Hill JJ. Mind reading: the interactive guide to emotions. In: Mind reading: the interactive guide to emotions. London: Jessica Kingsley Limited; 2004 (www.jkp.com).

44. Forster KL, Forster JC. DMDX: a windows display program with millisecond accuracy. Behav Res Methods Instrum Comput. 2003;35:116-24.

45. Williams J, Scott FJ, Stott CM, Allison C, Bolton P, Baron-Cohen S, et al. The CAST (Childhood Asperger Syndrome Test): test accuracy. Autism. 2005;9:45-68.

46. Williams J, Allison C, Scott FJ, Stott CM, Bolton P, Baron-Cohen S, et al. The Childhood Asperger Syndrome Test (CAST): test-retest reliability. Autism. 2006;10:415-27

47. Baron-Cohen S, Jolliffe T, Mortimore C, Robertson M. Another advanced test of theory of mind: evidence from very high functioning adults with autism or Asperger syndrome. J Child Psychol Psychiatry. 1997:38:813-22 
48. Wechsler D. Wechsler Abbreviated Scale of Intelligence (WASI) - UK version. Oxford: Pearson Assessment; 1999.

49. Baron-Cohen S, Spitz A, Cross P. Can children with autism recognize surprise? Cognition and Emotion. 1993;7:507-16.

50. Harris PL. The child's understanding of emotion: developmental change and the family environment. J Child Psychol Psychiatry. 1994;35:3-28

51. Izard CE. Translating emotion theory and research into preventive interventions. Psychol Bull. 2002;128:796-824.

52. Klin A, Jones W, Schultz R, Volkmar F, Cohen DJ. Visual fixation patterns during viewing of naturalistic social situations as predictors of social competence in individuals with autism. Arch Gen Psychiatry. 2002;59:809-16

53. Zeelenberg M, van Dijk Wilco W, Manstead ASR, der Pligt J. The experience of regret and disappointment. Cognition \& Emotion. 1998;12:221-30.

54. Hillier A, Allinson L. Understanding embarrassment among those with autism: breaking down the complex emotion of embarrassment among those with autism. J Autism Dev Disord. 2002;32:583-92.

55. Ashwin C, Baron-Cohen S, Wheelwright S, O'Riordan M, Bullmore ET. Differential activation of the amygdala and the 'social brain' during fearful face-processing in Asperger syndrome. Neuropsychologia. 2007:45:2-14.

56. Sigman MD, Kasari C, Kwon JH, Yirmiya N. Responses to the negative emotions of others by autistic, mentally retarded, and normal children. Child Dev. 1992;63:796-807.

57. Lacroix A, Guidetti M, Rogé B, Reilly J. Facial emotion recognition in 4- to 8-year-olds with autism spectrum disorder: a developmental trajectory approach. Research in Autism Spectrum Disorders. 2014;8:1146-54.

58. Carroll N. Comic amusement, emotion, and cognition. On Emotions: Philosophical Essays 2013:76-98

59. Aubergé V, Cathiard M. Can we hear the prosody of smile? Speech Comm. 2003:40:87-97.

60. Sofronoff K, Dark E, Stone V. Social vulnerability and bullying in children with Asperger syndrome. Autism. 2011;15:355-72.

61. van Roekel E, Scholte RH, Didden R. Bullying among adolescents with autism spectrum disorders: prevalence and perception. J Autism Dev Disord. 2010;40:63-73.

62. Baron-Cohen S, Wheelwright $\mathrm{S}$, Jolliffe $\mathrm{T}$. Is there a "language of the eyes"? Evidence from normal adults, and adults with autism or Asperger syndrome. Vis Cogn. 1997;4:311-31.

63. Akechi H, Senju A, Kikuchi Y, Tojo Y, Osanai H, Hasegawa T. The effect of gaze direction on the processing of facial expressions in children with autism spectrum disorder: an ERP study. Neuropsychologia. 2010;48:2841-51.

64. Pelphrey KA, Morris JP, McCarthy G. Neural basis of eye gaze processing deficits in autism. Brain. 2005;128:1038-48.

65. Globerson E, Amir N, Kishon-Rabin L, Golan O. Prosody recognition in adults with high-functioning autism spectrum disorders: from psychoacoustics to cognition. Autism Res. 2014. doi:10.1002/aur.1432

66. Grossman RB, Tager-Flusberg H. Who said that? Matching of low- and high-intensity emotional prosody to facial expressions by adolescents with ASD. J Autism Dev Disord. 2012;42:2546-57.

67. Goin-Kochel RP, Mazefsky CA, Riley BP. Level of functioning in autism spectrum disorders: phenotypic congruence among affected siblings. J Autism Dev Disord. 2008;38:1019-27.

68. Constantino JN, Lajonchere C, Lutz M, Gray T, Abbacchi A, McKenna K, et al. Autistic social impairment in the siblings of children with pervasive developmental disorders. Am J Psychiatry. 2006;163:294-6.

69. Gotham K, Risi S, Pickles A, Lord C. The Autism Diagnostic Observation Schedule: revised algorithms for improved diagnostic validity. J Autism Dev Disord. 2007:37:613-27.

70. Lacava PG, Rankin A, Mahlios E, Cook K, Simpson RL. A single case design evaluation of a software and tutor intervention addressing emotion recognition and social interaction in four boys with ASD. Autism 2010;14:161-78

71. Lopata C, Thomeer ML, Volker MA, Lee GK, Smith TH, Smith RA, et al. Feasibility and initial efficacy of a comprehensive school-based intervention for high-functioning autism spectrum disorders. Psychol Sch. 2012;49:963-74.
72. Ramdoss S, Machalicek W, Rispoli M, Mulloy A, Lang R, O'Reilly M. Computer-based interventions to improve social and emotional skills in individuals with autism spectrum disorders: a systematic review. Dev Neurorehabil. 2012;15:119-35.

73. Spencer M, Holt R, Chura L, Suckling J, Calder A, Bullmore E, et al. A novel functional brain imaging endophenotype of autism: the neural response to facial expression of emotion. Translational psychiatry. 2011;1, e19.

\section{Submit your next manuscript to BioMed Central and take full advantage of:}

- Convenient online submission

- Thorough peer review

- No space constraints or color figure charges

- Immediate publication on acceptance

- Inclusion in PubMed, CAS, Scopus and Google Scholar

- Research which is freely available for redistribution 